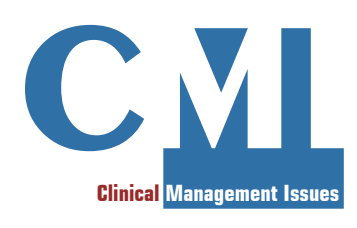

\title{
S.VA.M.Di.: a new opportunity for the National Health System
}

\begin{abstract}
Multi-dimensional assessment is still evolving today. Object of our study is not only the transition from the S.Va.M.A form ("Scheda per la valutazione multidimensionale dell'anziano»Questionnaire for multidimensional evaluation of the elderly) to the S.Va.M.Diform ("Scheda di valutazione multidimensionale del disabile» - Questionnaire for the multidimensional assessment of disabled individuals), but the administration of S.VA.M.Di to subjects included in a «PAI» ("Piano assistenziale individuale» - Individual Assistance Plan). This integration is designed to facilitate the access of patients to home care, integrated home care and residential and semi-residential care.

During 2015 the S.VA.M.Di questionnaire was administered on an experimental basis within the Adult Disability Service of ASL Viterbo to a random mode selected sample of 108 residents of the Viterbo province with a diagnosis of mental retardation (mild, moderate, moderate) severe and severe).

S.VA.M.Di is an anamnestic, diagnostic, evaluative and prescriptive tool, useful for an integrated approach in the patient's care in the health, social health and / or social dimensions; it is a tool that describes the decision processes and allows statistical and epidemiological analysis. The analysis of the results showed that the S.VA.M.Di is certainly a very complex questionnaire to be completed, in terms of working hours devoted to the writing and the complexity in processing. However, it has considerable advantages as regards the completeness and accuracy of the data collected. Essential for its implementation and adoption is the adequate training of health professionals involved.
\end{abstract}

Keywords: Multi-dimensional assessment; Mental retardation; PAI (Piano assistenziale individuale); S.VA.M.Di. (Scheda di valutazione multidimensionale del disabile); Disability S.VA.M.Di.: una nuova opportunità per il Servizio Sanitario Nazionale CMI 2016; 10(3): 63-67

bttp://dx.doi.org/10.7175/cmi.v10i3.1265

\section{INTRODUCTION}

Multi-dimensional assessment is still evolving today, as reflected by the different questionnaires which are used for social and health services. In Italy multi-dimensional assessment questionnaires are activated by general practitioners and pediatricians as a result of the access to the social and health care system through the «PUA» («Punto unico di accesso»-Single access point). They are organized by the social and rehabilitation district which always acts on behalf of the district director. The evaluation and taking charge carried out by the «UVMA» («Unità di valutazione multidimensionale distrettuale»-District multidimensional assessment unit) also serves as a monitoring and database tool [1].

In Italy there are two main tools used for this purpose: the S.Va.M.A form («Scheda per la valutazione multidimensionale dell'anziano» - Questionnaire for multidimensional evaluation of the elderly) and the
${ }^{1}$ UOS Formazione,

ASL Viterbo

2 Corso di Laurea

Magistrale in

Scienze Riabilitative

delle Professioni

Sanitarie, Università

La Sapienza, Roma

${ }^{3}$ Coordinamento

Vaccinazioni,

Dipartimento di

Prevenzione, ASL

di Viterbo

${ }^{4}$ Dipartimento per il

Governo dell'Offerta

e Cure Primarie,

ASL di Viterbo
Corresponding author Silvia Dari

silvia.dari@asl.vt.it

Disclosure

The authors declare they have no competing financial interests

concerning the topics of this article 
S.Va.M.Di form ( Scheda di valutazione multidimensionale del disabile» - Questionnaire for the multidimensional assessment of disabled individuals). Both forms have been created in the Veneto Region.

In 1999 the Veneto Region approved S.VA.M.A for the elderly, valid for the whole region, and used it for the definition of the self-sufficiency and for access to home and residential care services [2]. S.VA.M.A did not sufficiently describe the disability of the user, and the Veneto Region introduced a first version of the S.VA.M.Di, based on the ICF (International Classification of Functioning, Disability, and Health) framework, testing it in 10 Local Health Care Systems (A.ULSS) of the Region [3-4]. At the end of this first trial, the Veneto Region approved the use of S.VA.M.Di throughout the whole region and introduced the questionnaire in the UVMA [1] with the aim to define individual plans, synthetic profiles and priorities for access to services for users with disabilities. In August 2007, the Veneto Region launched a special experimental project, in order to validate the evaluation system, to produce measurable and comparable results, and to manage the waiting lists. The scientific responsibility of this trial was entrusted to the Centre Don Calabria in Verona [5]. From 2007 to 2009, the S.VA.M.Di was used in the Veneto Region and an updated version was made official [6]. In addition, the «Osservatorio Regionale» (Regional Observatory) was involved in the project, with a dual task: a) to establish training courses for the operators; $b$ ) to coordinate the management of the questionnaire through the web, by facilitating the access to ICD-X (International Classification of Diseases 10th Revision) and ICF [7]. In those years, an extended use of the questionnaire was implemented in every sphere of adulthood, including evaluation, taking charge, access to residential and semi-residential care services, interventions and services provided by regional law and labor integration. Between September and December 2009, a training for all Local Health Care Systems (A.ULSS) was organized, selecting a contact in the healthcare area and one in the social area, who in turn become trainers, thereby enlarging the analyzed sample to $1,500 \mathrm{ca}-$ ses [3]. At last, in 2012 the S.VA.M.Di was introduced in the Veneto Region [8], with all the changes and additions made to the previous official version [6]. After years of trial, it reaches its final form in 2014 [3,9].
Several Italian Regions, including Valle d'Aosta, Calabria, Campania, Puglia and Lazio, have adopted it.

The S.VA.M.Di questionnaire is developed on the ICF structure and conceptual organization and completes the ICD-X classification, including information on diagnosis and etiology of the disease. The ICF is structured into four main components: body functions, body structures, activities and environmental factors $[10,11]$. The S.VA.M.Di includes 137 codes (ICF Checklist Adults), in which the interaction between ability and disability of a person is seen in terms of process or results. It consists of 4 sections which include $[3,4,7,10,11]$ :

- part 1a, impairments of the body functions;

- part 1b, impairments of body structures (compiling $1 \mathrm{a}$ and $1 \mathrm{~b}$ rests with a doctor)

- part 2, limitations (to be compiled by a psychologist or professional educator/ therapist);

- part 3, environmental factors;

- part 4, more information about the context (part 3 and 4 are compiled by a social worker or a professional educator therapist - the same as part 2);

- social evaluation (to be compiled by a social worker).

It can be accompanied by additional descriptive pages of relevant situations.

The questionnaire is aimed mainly at improving access to the system of services and not primarily for case management. In addition, it can also be useful to have a first picture of the user's economic situation and, as a result, to quantify the welfare and rehabilitation charge for the National Health System.

Following the participation of some healthcare professionals to a conference on the use of S.VA.M.Di held in 2015 at the Opera Don Calabria in Rome [12], the S.VA.M.Di has been the subject of study by the Adult Disability Service ( Servizio Disabile Adulto») of the Local Health Authorities (ASL) of Viterbo. Besides, professionals have felt the need to update and discuss the method of use of the «PAI» («Piano assistenziale individuale» / Individual Assistance Plan) which is also based on ICF, and its integration with the S.VA.M.Di, as an aid to facilitate the access of patients to home care services, residential and semi-integrated care.

The PAI was adopted by the Adult Disability Service of ASL Viterbo in 2012, with 
the taking charge of the users of the services of children neuropsychiatry ( Neuropsichiatria Infantile» - NPI) when they turn 18 and join the adult users group. The PAI is developed by a team and is a summary document that collects and describes in a multidisciplinary perspective the assessment of each user, in order to start an assistance, care and rehabilitation plan for a specific user $[13,14]$.

Object of the present study is not only the transition from S.Va.M.A form used for elderly people to the S.Va.M.Di form used for people with disabilities, but also the application of the S.Va.M.Di form to subjects included in the PAI [3].

\section{MATERIALS AND METHODS}

During 2015 the S.VA.M.Di questionnaire was administered on an experimental basis within the Adult Disability Service of ASL Viterbo to a random mode selected sample of 108 residents of the Viterbo province with a diagnosis of mild, moderate, moderate/severe and severe mental retardation. Many patients present comorbidity with other diseases and all are subject to a PAI, carry out rehabilitative and welfare activities, and some of them take part in social rehabilitation training. The S.VA.M.Di form was administered by professional members of a highly specialized team, composed of doctors, psychologists, therapists, social workers and other rehabilitation professio-

\begin{tabular}{|l|c|c|c|}
\hline \multicolumn{1}{|c}{ Patients } & Male & Female & Total \\
\hline Number & 62 & 46 & 108 \\
Average age & 32 & 34 & 33 \\
Age range & $19-56$ & $20-66$ & $19-66$ \\
\hline
\end{tabular}

nals. The scenario has been identified and processed through Windows Access and Excel. The results were expressed as mean, range, and ratios.

\section{RESULTS}

As reported in Table I, the population consists of 108 people, the average age is 33 years and the age range is between 19 and 66 . There is a predominance of males, $57 \%$ of the total.

Table II highlights that half of the males are between 18 and 29 years old, while the older patient (66 years) is a female. In general, the 18-29 age group is the most populous (51 patients).

Table III represents the clinical situation of the sample: a moderate mental retardation is seen in $53 \%$ of cases.

$58 \%$ of patients present comorbidity with other diseases (for example, the most frequent are Down syndrome, autism, language and/or motor deficit). As to work, only 6\% ( 3 females and 4 males) have an employment as laborer, hospital auxiliary worker or shop assistant.
Table I. Distribution

by sex

\begin{tabular}{|c|c|c|c|c|c|c|}
\hline \multirow{3}{*}{ Age } & \multicolumn{3}{|c|}{ Male } & \multicolumn{3}{c|}{ Female } \\
\cline { 2 - 7 } & $\mathbb{N}$ & $\%$ & $\mathbb{N}$ & $\%$ & $\mathbb{N}$ & $\%$ \\
\hline $18-29$ & 31 & 50 & 20 & 43 & 51 & 47 \\
$30-39$ & 19 & 31 & 11 & 24 & 30 & 28 \\
$40-49$ & 9 & 15 & 11 & 24 & 20 & 19 \\
$50-59$ & 3 & 5 & 3 & 7 & 6 & 6 \\
$60-69$ & 0 & 0 & 1 & 2 & 1 & 1 \\
\hline
\end{tabular}

Table II. Distribution by age group, according to sex

\begin{tabular}{|c|c|c|c|c|c|c|}
\hline \multirow{2}{*}{ Clinical situation } & \multicolumn{2}{|c|}{ Male } & \multicolumn{2}{|c|}{ Female } & \multicolumn{2}{|c|}{ Total } \\
\hline & N & $\%$ & N & $\%$ & N & $\%$ \\
\hline Mild mental retardation & 21 & 34 & 16 & 35 & 37 & 34 \\
\hline Moderate mental retardation & 32 & 52 & 25 & 54 & 57 & 53 \\
\hline Moderate/severe mental retardation & 4 & 6 & 3 & 7 & 7 & 6 \\
\hline Severe mental retardation & 5 & 8 & 2 & 4 & 7 & 6 \\
\hline
\end{tabular}

Table III. Distribution by clinical situation, according to sex 


\section{DISCUSSION AND CONCLUSION}

The difference between the S.VA.M.A and the S.VA.M.Di is the introduction of disability: in fact, in S.VA.M.A disability is omitted in all aspects $[3,7,4]$. Environmental factors are at the same time "facilitators" and "barriers" of the person's well-being, and their analysis is essential for territorial/regional planning in order to access services $[7,10]$. For these reasons, the questionnaire has been restructured in order to identify the environmental factors that have a direct impact on the choice of the service, and the thresholds to access care and welfare services to be provided by the Region have been determined on the basis of the S.VA.M.Di assessment [4].

The professionals who collected data and processed the S.VA.M.Di encountered difficulties in terms of working hours devoted to the writing and the complexity in processing. However, after the initial effort, the completeness and accuracy of the S.VA.M.Di became clear, even though it requires a big effort and a high level of preparation on the part of professionals.

Table IV reports the differences between PAI and S.VA.M.Di. Although the S.VA.M.Di provides more information on the patient, the two questionnaires are complementary and the one can be considered as an integral part of the other. While the PAI explicitly and concisely indicates the objectives and actions to be taken, the S.VA.M.Di is an anamnestic, diagnostic, evaluative and prescriptive tool, useful for an integrated approach in the care of the health, social health and /or social dimensions; a tool that describes the decision processes and allows statistical and epidemiological analyses.

During the trial, many strong points of S.VA.M.Di emerged:
- S.VA.M.Di can provide a swift response to the requests of the user, whose complete medical history is recorded at the time of the taking charge;

- it is based on the ICF, which provides an universal language for professionals, through codes and qualifiers which serve as reference for the description of health and related health status (the ICF is also used in PAI $[7,10])$;

- it offers an integration of the disability, unlike the S.VA.M.A form, used for the elderly;

- it provides a common language that considers the disabled person in terms of operation and available resources;

- it is a valuable aid to supplement data collection for the drafting of a PAI;

- it facilitates access to services regulated by the National Health System, bringing benefits to both the service that drafts it and the patient in the development of a personalized plan;

- since it can be administered only by previously trained staff, there is a reduction of evaluation bias.

A point of weakness was the difficulty encountered in the administration and in the compilation of the questionnaire, given the lack of adequate specific and practical training on the part of all staff; therefore, before a new trial is undertaken or a possible official adoption of the questionnaire is envisaged, it is necessary to provide a medical continuing education (MCE) training on this tool. For example, the Lazio Region has shown an interest in this training requirement by the health professionals including in the regional MCE training plan for the 2016/2018 an area specifically dedicated to the multidimensional assessment, the PAI and the
Table IV. Comparison between PAI and S.VA.M.Di
PAI

S.UA.M.Di

- Date (compilation date)

- Name and surname

- Place and date of birth

- Address

- Phone

- Tax code

- Legal status (interdiction)

- Doctor

- Diagnosis

- Disability Profile (cod. ICF)

- PAl objectives

- Measures to be implemented
- Personal data (like PAl, but in addition sex, check and follow-up, co-pay fee exemptions, social security card, citizenship, doctor who referred the patient to the service)

- Contact (general practitioner / pediatrician, reference person)

- Health assessment (current diagnosis, summary information, nursing)

- Functional assessment (part 1a, 1b)

- Social assessment (marital status, education, school attended, work experience, current employment status, certifications, family background, living and economic situation)

- Multidimensional assessment result (assessment team)

- Reassessment of welfare and care needs (verification outcome, evaluation team, further planned verification) 
S.VA.M.Di (Area number 5 «Cronicità e fragilità»-Chronicity and fragility) [15].

Similarly, it is desirable that the ASL Viterbo as MCE provider will be able to set up specific training courses dedicated to the adult disability service staff and to other services that deal with the adult disability, with the aim to raise awareness, understanding and learning the use of this assessment tool.

In conclusion, S.VA.M.Di is a valuable aid that complements and does not replace the drafting of the PAI, reinforcing the clinical and bio-psychosocial knowledge of the user $[3,4,7,10,11]$ because the district multidimensional assessment is a priority in the access of the patient to care. Its elaboration should therefore become necessary to provide access to care services. The adoption of this tool for evaluating patients referred to adults with disability services presents clinical, organizational and economic advantages for patients, for the ASL and for the society.

\section{BIBLIOGRAFIA}

1. Deliberazione della giunta regionale del Veneto n. 331 del 13 febbraio 2007. Valutazione multidimensionale delle persone con disabilità secondo ICF, Classificazione Internazionale del Funzionamento, della Disabilità e della Salute: approvazione e introduzione di S.Va.M.Di per l'accesso ai servizi sociali e socio sanitari. Bur n. 22 del 02 marzo 2007. Available on http://bur.regione. veneto.it/BurvServices/pubblica/DettaglioDgr.aspx?id=195364 (last accessed September 2016)

2. Deliberazione della giunta regionale 3979 del 9 novembre 1999. Valutazione multidimensionale dell'adulto e dell'anziano. Approvazione scheda S.V.A.M.A.

3. Bollori S. Sperimentazione della scheda multidisciplinare S.Va.M.Di. introdotta dalla Regione Veneto. A.ULSS 5 ovest vicentino. Available on http://www.bottegadelpossibile.it/wp-content/ uploads/2013/12/15-Sabrina-Bollori-relazione.pdf (last accessed September 2016)

4. Bollettino Ufficiale della Regione Veneto n. 13 del 3 febbraio 2015. Available on http://bur. regione.veneto.it (last accessed September 2016)

5. Deliberazione della giunta regionale del Veneto n. 2632 del 2 agosto 2007

6. Deliberazione della giunta regionale del Veneto n. 2575 del 4 agosto 2009. Individuazione e approvazione dei criteri per la messa a regime della nuova Scheda di Valutazione Multidimensionale Disabili (SVaMDi). Bur n. 78 del 22 settembre 2009. Available on http:// bur.regione.veneto.it/BurvServices/pubblica/DettaglioDgr.aspx?id=217824 (last accessed September 2016)

7. Materiali Formazione Regionale ICF. Dalla SVaMDi al Progetto di Vita. Centro Don Calabria, Verona, 2009

8. Deliberazione della giunta regionale del Veneto n. 2960 del 28 dicembre 2012. Approvazione modifiche ed integrazioni alla scheda SVaMDi di cui alla DGR 2575 del 4 agosto 2009. Available on http://bur.regione.veneto.it/BurvServices/pubblica/DettaglioDgr.aspx?id=245515 (last accessed September 2016)

9. Deliberazione della giunta regionale del Veneto n. 1804 del 6 ottobre 2014. Approvazione del documento "Linee Guida per la codifica ICF e compilazione della Scheda di valutazione multidimensionale SVaMDi”, del modello della SVAMDi aggiornato semanticamente al linguaggio ICD e dell'algoritmo per il calcolo dei punteggi di gravità e di funzionamento esitati SVaMDi. Available on http://extraospedaliero.regione.veneto.it/provvedimenti (last accessed September 2016)

10. Organizzazione Mondiale della Sanità. ICF Classificazione Internazionale del funzionamento della disabilità e della salute. Trento: Edizioni Centro Studi Erickson, 2002

11. Regolamento UVMD Ulss 5 Ovest Vicentino. Approvato dal Consiglio di Distretto del 10 Giugno 2010. Available on http://www.ulss5.it/binary/ulss5/regolamenti_doc/UVMD_ULS_5_ OVEST_VICENTINO.1291044102.pdf (last accessed September 2016)

12. Atti del convegno "Che cos'è la SVAMDI?". Opera Don Calabria, Roma, 27 febbraio 2015

13. Legge 5 febbraio 1992, n. 104. Legge-quadro per l'assistenza, l'integrazione sociale e i diritti delle persone handicappate. Gazzetta Ufficiale del 17 febbraio 1992, n. 39, Supplemento Ordinario

14. Legge regionale n. 20 del 23 novembre 2006. Regione Lazio. Istituzione del fondo regionale per la non autosufficienza. Bollettino ufficiale della Regione Lazio n. 34 del 9 dicembre 2006

15. Regione Lazio. Piano formativo regionale triennio 2016/2018. Indirizzi strategici per la formazione degli operatori sanitari. Available on https://www.regione.lazio.it/binary/rl_sanita/ tbl_contenuti/piano_formativo_2016_2018.pdf (last accessed September 2016) 